\title{
List of Manuscript Material Now Available
}

The List of Business Manuscripts in Baker Library, referred to more fully in the May Bulletin, is now available at fifty cents a copy on application to Baker Library, Harvard Graduate School of Business Administration, Soldiers Field, Boston, Massachusetts. The list (II 2 pages), published by the Library, includes descriptions of both the material collected by the Business Historical Society and the Library itself -508 collections in all.

\section{"The Glasgow University Press$$
\text { 1638-1931" }
$$

Amovg the more recent volumes received by the Business Historical Society is The Glasgow University Press $1638-1931$ by James Maclehose. The author, himself a member of the family that now runs the press, enters into his task with uncommon enthusiasm.

The University Press of Glasgow, unlike those of Oxford and Cambridge, has always been privately owned. This rather complicates the work of writing its history. The administration of the press, over this period of nearly three hundred years, was undertaken by no less than fourteen different families, not to mention the various members of some of those families. For this reason, it is impossible to find any real development of policy.

For the first hundred years the history of the press seems to be woven around a struggle which involved a series of privileges, Royal grants, monopolies, exemptions, drawbacks, family quarrels, etc., but with the entrance of Robert Foulis into the account there comes a new tone. Here we have the press adopting methods which brought fame not only to the press but to the University itself. The type which he developed and the care with which the work of printing was conducted produced some of the most beautiful books ever printed. He demanded not only beauty of the printed page, but the greatest accuracy. He required five proof readings in an effort to eliminate all error, concerning which our author says, "This is the way in which really great work is done; 